\title{
Geometric accounts of consonant-vowel interactions in developing systems
}

\author{
JUDITH A. GIERUT \\ Department of Speech and Hearing Sciences, Indiana University, Bloomington, \\ IN 47405, USA
}

\author{
MI-HUI CHO and DANIEL A. DINNSEN \\ Department of Linguistics, Indiana University, Bloomington, IN 47405, USA
}

(Received 14 December 1992; accepted 3 March 1993)

\begin{abstract}
Phenomena associated with consonant-vowel interactions are examined relative to three general models of feature geometry which differ in the planar relationship of consonants and vowels. The data come from reports of developing phonological systems, both normal and disordered. Geometric analyses reveal that consonants and vowels are fully integrated in the earliest stages of development such that the place specification of consonants is primarily derived from the vowel. However, change through development requires modifications either in the principles of place association, the degree of feature specification, or the planar representation of consonants and vowels.
\end{abstract}

Keywords: Feature geometry, consonant-vowel interactions, phonological development.

\section{Introduction}

Within current phonological theory, feature geometry is one framework that has been advanced to account for the representation and interaction of specific segments and features. There have been numerous proposals regarding the properties and structures needed to constitute an adequate feature geometry (e.g. Clements, 1985; McCarthy, 1988; Sagey, 1986). These have evolved mainly from examinations of assimilations, dissimilations, and the effects of the obligatory contour principle in fully developed primary languages. Proposed geometries have attempted to account for such processes as they affect either consonants or vowels, and the interactions of these in adjacent and non-adjacent segments.

To date there has been little attention given to issues of phonological acquisition in feature geometry. Moreover, the limited research that has been done has focused almost exclusively on the consonantal reportoires of children. Specifically, Stemberger and Stoel-Gammon (1991) appealed to feature geometry in order to account for the frequency of coronal (as opposed to labial or dorsal) place assimilations in normally developing phonologies. Dinnsen (1992a) and Chin and Dinnsen $(1991,1992)$ demonstrated that feature geometry was useful in accounting for other observed developmental phenomena, including systematic phonetic correspondences 
between target and child systems, differential patterning of phonetically identical segments. consonant coalescences. and alternations of affricates with fricatives and alveolar stops with glottal stops. Bernhardt (1992a,b; Bernhardt and Gilbert, 1992) focused on children with phonological disorders in the extension of feature geometry to the clinical treatment of errored consonants. Finally. Rice and Avery (1991) and Rice (1992) proposed a model of feature geometry that was hypothesized to account for the development of consonant inventories. Although they relied solely on typological evidence from fully developed primary languages, they predicted that the specificity of their geometry would increase monotonically with inventory size, in much the same way that children progress from having less complex to more complex segments in their repertoire.

Despite the paucity of research. the study of phonological acquisition offers a unique testing ground for proposals of feature geometry. It has been well established that initially children's phonological representations are different from the ambient language, such that there are mismatches between the child's system and the adult target (e.g. Gierut. 1986, 1989; Leonard and Brown, 1984; Weismer, Dinnsen and Elbert. 1981). These mismatches diminish with time and development, suggesting that the nature of children's phonological representations changes to more closely parallel the target system. An examination of phonological acquisition may help to establish the range of feature geometries that are possible in language, and to identify which model (or models) is to be preferred. Furthermore, potential changes in the geometric representation that occur with development can be traced.

The purpose of this paper is to evaluate competing models of feature geometry from the perspective of phonological acquisition, both normal and disordered. More specifically, the interaction of consonants and vowels in development will be examined relative to three geometric models that have been advanced for fully developed primary languages, but that differ crucially in the planar relationship of features for consonants and vowels. A brief review of these geometries is presented first, followed by analyses of consonant vowel interactions reported in phonological acquisition. Results of these analyses are then discussed relative to their implications for phonological acquisition and for the theory of feature geometry.

\section{Competing models of feature geometry}

There are three logically possible ways in which consonants and vowels may be represented and may interact in a linguistic system. Specifically, the place features for consonants and vowels may be represented on the same tier and, as such, may be interdependent and free to interact. A representational structure of this type involves the full integration of the consonant and vowel place features, as illustrated by the geometry of Lahiri and Evers (1991) shown in Figure 1. ${ }^{1} \mathrm{~A}$ full integration model has the advantage of being able to describe interactions of phonetically adjacent consonants and vowels, whereby the place feature of a consonant spreads to an adjacent vowel, or vice-versa, as shown in Figure 2. A fully integrated geometry

\footnotetext{
${ }^{1}$ In this and subsequent geometries. only relevant structure is displayed. Also, the particular geometries presented are not exclusive, but rather serve only to illustrate the possible relationships between consonants and vowels as outlined by the theory. Finally, details about the substantive features of any particular proposal and the degree of feature specification do not bear crucially on the discussion.
} 


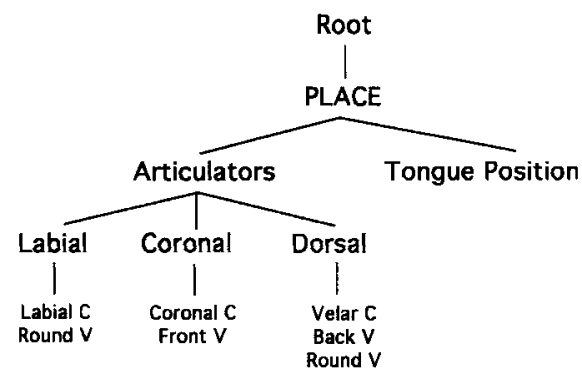

Figure 1. Fully integrated feature geometry adapted from Lahiri and Evers (1991). (Note: C refers to consonants and $V$ to vowels.]

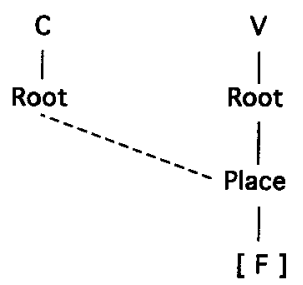

Figure 2. Spreading to phonologically and phonetically adjacent segments within a fully integrated model of feature geometry. [Note: [F] refers to feature.]

has limitations, however, in that it cannot account for the spreading of place to phonetically non-adjacent segments when the intervening segment is also specified for place. In such cases the intervening specification of place will block feature spreading to non-adjacent segments given the well-formedness condition which prevents the crossing of association lines (Goldsmith, 1979).

Alternatively, the place features for consonants and vowels may be totally independent and represented on non-interacting tiers. This geometric structure involves the full segregation of the consonant and vowel place features, as in Clements's geometry (1989) shown in Figure 3. A full segregation model provides for the spreading of place features to phonetically adjacent and like segments, that is, from neighbouring vowel-to-vowel, or consonant-to-consonant. This model has a further advantage of allowing feature spreading to phonetically non-adjacent but like segments, as depicted in Figure 4. In contrast to the fully integrated model (described above), there is no blocking effect of intervening segments in this geometry given C-place (or alternatively, V-place) tier adjacency. Despite these advantages, there is one noted difficulty for a fully segregated geometry. In principle, full segregation

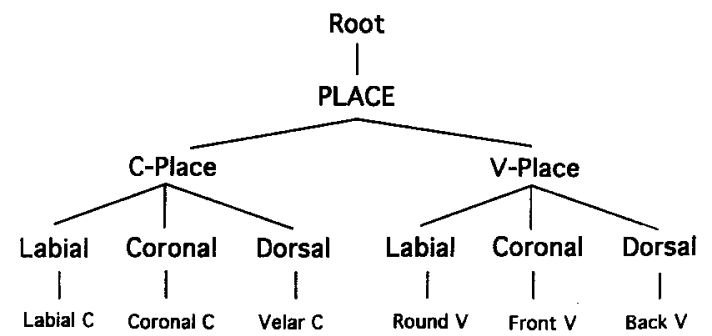

Figure 3. Fully segregated feature geometry adapted from Clements (1989). 


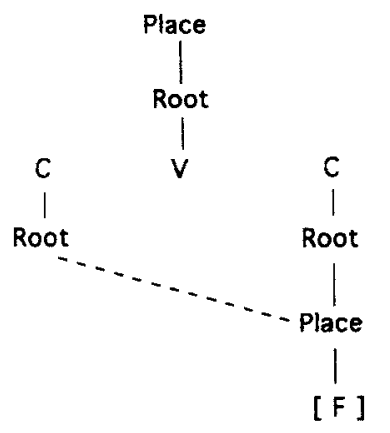

Figure 4. Spreading to phonologically adjacent but phonetically non-adjacent segments within a fully segregated model of feature geometry.

prohibits the spreading of place to segments that are not of the same type, as in vowel-to-consonant or consonant-to-vowel interactions. In these cases the spreading feature of the C-place must somehow first be linked to the V-place (or vice-versa). ${ }^{2}$

As a compromise to the extremes of full integration versus full segregation, a third possibility involves the partial segregation of the place features for consonants and vowels. Here, the consonant and vowel place features are arranged on different tiers, but overlap given the location of the C-place relative to the V-place. Figure 5 shows the V-place subordinate to the C-place as in Clements's (1991) partially segregated geometry. ${ }^{3}$ Given a CVCV sequence then, place features of a vowel can spread to a phonetically adjacent consonant (or vice-versa). This is shown in (a) of Figure 6. Also, place features can spread to non-adjacent vowels because the intervening C-place node would not block the spreading, as in (b) of Figure 6. However, it

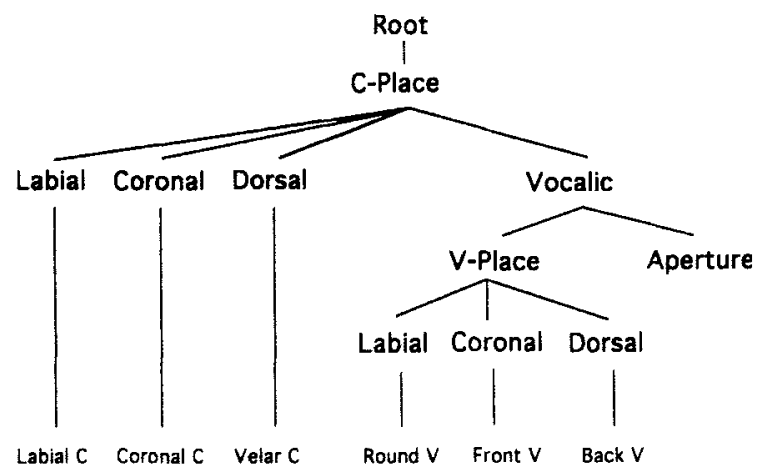

Figure 5. Partially segregated feature geometry adapted from Clements (1991).

\footnotetext{
${ }^{2}$ To motivate the linking of the $\mathrm{C}$ - and $\mathrm{V}$-places, Clements proposed the process of tier promotion. Tier promotion is questionable, however, because its trigger is not obvious and it appears to be an ad-hoc process (Lahiri and Evers, 1991).

${ }^{3}$ It is also possible that the C-place could be positioned lower than the V-place in a partially segregated geometry. However, the spreading of a vowel feature is more common than that of a consonant feature in fully developed primary languages, as evidenced by phonetically non-adjacent vowel harmony and secondary articulations (e.g. Schein and Steriade, 1986; Steriade, 1987). To express the fact that place feature of vowels spread freely across intervening consonants, but place features of consonants rarely spread across intervening vowels, the $\mathrm{V}$-place node has typically been subordinate to the C-place node in contemporary geometries.
} 
(a)

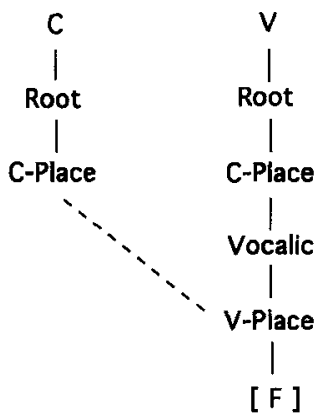

(b)

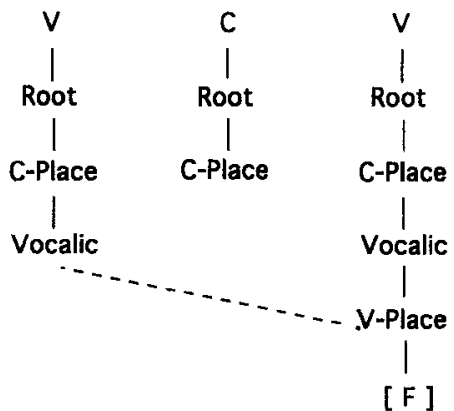

Figure 6. Spreading within a partially segregated model of feature geometry. In (a) spreading is illustrated for phonologically and phonetically adjacent segments; in (b) it is illustrated for phonologically adjacent but phonetically non-adjacent segments.

is not possible in a partially segregated geometry for place to spread to phonetically non-adjacent consonants, as might be required for putative cases of consonant place harmony. Here, the place of intervening vowels would block the spreading of $\mathrm{C}$-place features (see, however, Hume, 1992).

In summary, there are three competing persepectives on the representation of the consonant and vowel place features within feature geometry for fully developed primary languages. The geometries are similar in that they appeal to a unitary set of place features for consonants and vowels, as grouped together by natural class. That is, labial consonants and round vowels are organized at the labial node, coronal consonants and front vowels at the coronal node, and velar consonants and back vowels at the dorsal node. The models differ structurally in the array of these features on the same or different tiers. They also differ in their account of various kinds of consonant-vowel interactions. In the next section these alternative views of feature geometry will be considered relative to the interactions of consonants and vowels observed in phonological acquisition.

\section{Normal phonological acquisition}

Numerous reports have indicated that specific consonants and vowels pattern as natural classes in phonological acquisition. Beginning with normal development, Braine (1974) reported that his son Jonathan consistently produced alveolar consonants before front high vowels, as illustrated by the data in (1).

(1) Jonathan (20-23 months)

$\begin{array}{ll}\text { [di] } & \text { 'pee', 'B' } \\ \text { [di?] } & \text { 'big' } \\ \text { [didi] } & \text { 'baby' } \\ \text { [babadi] } & \text { '[bsb }{ }^{2} \text { b } \Delta \text { bi]' } \\ \text { [nI? ni?] } & \text { 'milk' }\end{array}$

A similar patterning of alveolars with front vowels was reported by Stoel-Gammon (1983; Stoel-Gammon and Dunn, 1985) (2). 
(2) Daniel

$\begin{array}{lll}\text { [didi] 'baby' } & (1 ; 2 \text { years }) \\ \text { [didi] 'pee-pee' } & (1 ; 4 \text { years })\end{array}$

Fudge (1969) also observed that his son frequently produced alveolar consonants with front vowels. Moreover, his child also produced consistently bilabial consonants with round back vowels, and further, when velars were added to the child's system, they occurred with back unround vowels (3).

(3) Fudge's son $(1 ; 4$ years)

\begin{tabular}{|c|c|}
\hline $\begin{array}{l}\text { [ti] } \\
\text { [den] }\end{array}$ & $\begin{array}{l}\text { 'a drink' } \\
\text { 'again' }\end{array}$ \\
\hline $\begin{array}{l}{[\text { bo }]} \\
{[\text { bo bo }]} \\
{[\text { bom }]} \\
\text { [mommo }\end{array}$ & $\begin{array}{l}\text { 'ball', 'book' } \\
\text { 'dog' } \\
\text { 'beating a drum' } \\
\text { 'Mummy' }\end{array}$ \\
\hline $\begin{array}{l}{[\mathrm{k} \wedge \mathrm{k}]} \\
{[\mathrm{g} \wedge \mathrm{g}]} \\
{[\mathrm{g} \wedge \mathrm{gu}]}\end{array}$ & $\begin{array}{l}\text { 'cake', 'truck' } \\
\text { 'garden' } \\
\text { 'doggie' }\end{array}$ \\
\hline
\end{tabular}

It is especially noteworthy in these examples that alveolar consonants were realized before front vowels even when the target consonant was labial or a velar. Likewise, labial and velar consonants surfaced before round and back vowels respectively, even when the target was an alveolar.

In addition to these descriptive reports, Kent and Murray (1982) noted in their acoustic study of infant vocalizations that coronal consonants and front vowels have a high frequeny of co-occurrence. Davis and MacNeilage (1990) also reported, in their quantitative analysis of vowel acquisition by one child, that each place of consonant articulation was associated with a preference for specific vowels. For this one child, the dominant pattern of co-occurrence involved alveolar consonants with front high vowels. Also, velar consonants occurred with back high vowels and labials, elsewhere.

Thus, across studies of normal phonological development, one early pattern that emerges is the association of place in consonants and vowels, namely, coronal with front, labial with round, and dorsal with back vowels. ${ }^{4}$ Notably, while these interactions of consonants and vowels have been observed in developing phonological systems, a theoretical account of the phenomenon is presently lacking. In this regard feature geometry may provide the necessary framework. In turn, its application to developing systems may serve to evaluate the power of competing geometries.

A first concern, however, relates to the specification of place in development. That is, is the place of consonants determined by adjacent vowels, or vice-versa?

\footnotetext{
${ }^{4}$ In a study by Vihman (1992) of the transition from babbling to first words, a correlation between consonant and rowel place of articulation was not observed. The absence of a correlation may be an artifact of having mixed meaningful speech with babbling. It may also be that these children already differentiated consonants from vowels as would ultimately be required for the target system.
} 
There is some evidence to suggest that it is the vowel place that influences consonant place. It is well established that vowels are acquired before consonants (Davis and MacNeilage, 1990; Jakobson, 1941/1968; Le Normand and Chevrie-Muller, 1991). Further, there are fewer errors in children's productions of vowels than consonants (Otomo and Stoel-Gammon, 1992). Consequently, it appears that vowels (and their corresponding place specification) may be firmly established before the same occurs for all consonants (Davis and MacNeilage, 1990, p. 26). Given this, it can be claimed that while young children know and specify the place of articulation of vowels, they do not yet specify consonant place. If this is the case, then interactions of consonants and vowels can best be characterized as a process of assimilation, such that place of articulation assimilates from vowels to consonants in the earliest periods of acquisition.

Considering next the three competing models of feature geometry, it appears that a proposal involving the full integration of consonant and vowel place features may be the most appropriate developmental representation (see also Levelt, 1992 for a similar claim regarding the acquisition of Dutch). ${ }^{5}$ The data in (1), (2), and (3) above support the tight linking of consonants and vowels. This is further illustrated by the representations and derivations shown in Figure 7. Notice that, in each of the examples, the place of the vowel is specified, but the place of the consonant is not. This is true even in more marked instances involving labial and dorsal consonants. Also, the spreading of place appears to be bidirectional, as evidenced in the forms [kık] 'cake', 'truck' and [den] 'again'.

A fully integrated model is preferred over other proposals of feature geometry in accounting for consonant-vowel interactions in development for several other reasons as well. First, within this model, the place features for consonants and vowels would be represented on the same tier, being interdependent and free to interact. This parallels directly the consistent assimilatory patterning of these segments in development. Second, if the hierarchical structure of a geometry reflects the order of acquisition such that superordinate elements are represented before subordinate elements (Bernhardt, 1992a,b; Rice, 1992), then the full integration model is consistent with the observed sequence of phonological acquisition. That is, vowels generally emerge before or concurrent with, but not subsequent to, consonant development. This is in contrast to a partially segregated geometry where the organizational structure may not correspond with the reported acquisition sequence. Within partial segregation, an earlier acquired V-place is positioned on a separate tier located subordinate to a yet-to-be-acquired $\mathrm{C}$-place. Third, full integration permits the free spreading of vowel place to phonetically adjacent consonants in the simplest, least restrictive way. This is distinct from a full segregation model where the $\mathrm{V}$ - and C-place tiers must first be associated before assimilation can take place.

To summarize, it appears that, in the early phases of normal phonological acquisition, the representation of consonants has no specification for place. Consequently, place features of vowels can spread to adjacent consonants. The model of feature geometry which best captures this interaction is the full integration of consonants and vowels. Stated another way, children seem to build a geometric representation that initially joins consonant place features and vowel place features on the same tier. The earliest rule of place assimilation can then be formulated as in (4). The formulation of this rule, however, does not necessarily imply that it is

\footnotetext{
${ }^{5}$ An alternative non-geometric account is that the place of articulation is a property of the word level (Iverson and Wheeler, 1987).
} 
(a) "ball," "book"

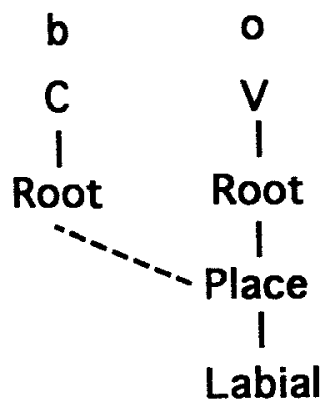

(b) "again"

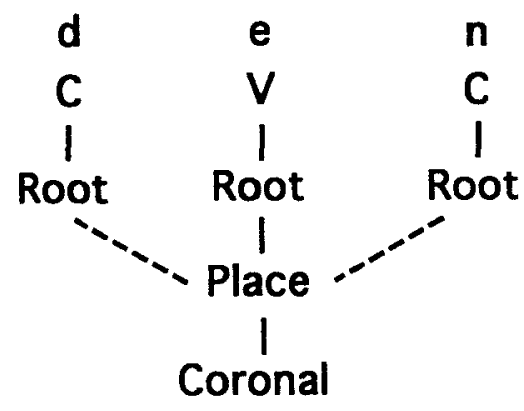

(c) "cake," "truck"

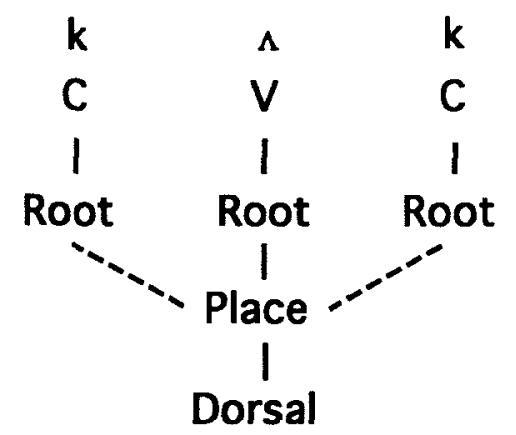

Figure 7. Derivations of forms produced by Fudge's son (1969) within a full integration model of feature geometry. The spreading of labial $(a)$, coronal $(b)$, and dorsal (c) place specifications of vouels is illustrated.

learned as a language-specific property. Rather, it may follow automatically from the underspecified character of consonants in the child's system.

(4) Place assimilation in phonological acquisition
(a) Trigger:
Vowels
(b) Target:
Consonants
(c) Operation: Spread the place feature
(d) Direction: Bidirectional 
In the next section, changes that occur with development in the fully integrated model of feature geometry can be further established by examining consonant and vowel interactions in older children identified as having phonological disorders.

\section{Delayed phonological acquisition}

Children with phonological disorders have been shown to have highly systematic rule-governed sound systems that, in the majority of cases, resemble structurally other possible natural languages (Dinnsen, 1992b; Ingram, 1989). Given this, it is possible to examine the sound systems of these children relative to those of their younger peers and relative to fully developed systems. These children thus provide a window onto the process of change in the course of acquiring language.

Specifically with regard to developmental changes in consonant-vowel interactions, two reported cases warrant discussion. Grunwell (1981) observed the patterning of coronal consonants and front vowels in a child S3, age 6;3, as illustrated by the data in (5). As in cases of younger normally developing children, assimilations in this child's system can be accounted for by the spreading of the place feature of the vowel to a preceding consonant not specified for place. However, unlike earlier phases of normal acquisition, this child's system exemplified three advances.

(5) $\mathrm{S} 3(6 ; 3$ years)

$\begin{array}{llll}{[\mathrm{t} \varepsilon \mathrm{k}]} & \text { 'peg' } & {[\mathrm{d} \varepsilon ə]} & \text { 'men' } \\ & & {[\mathrm{di}]} & \text { 'bee' } \\ {\left[\theta \varepsilon \varepsilon^{\prime}\right]} & \text { 'thread' } & {[ð \varepsilon \mathrm{k}]} & \text { 'leg' } \\ {[\theta \varepsilon ?]} & \text { 'head' } & {[ð \varepsilon]} & \text { 'red' } \\ {[\theta \mathrm{i}]} & \text { 'sea' } & {[ð \mathrm{i}]} & \text { 'wind' } \\ {[\theta \mathrm{r}]} & \text { 'feet' } & & \\ {[\theta \mathrm{I} \text { ? }]} & \text { 'ship' } & & \end{array}$

First, place assimilation was no longer limited to stop consonants, but also extended to fricatives. As displayed in Figure 8, when the consonant preceding a front vowel was not specified for place, but was specified for continuancy (or alternatively, continuancy and voice), it was realized as a corresponding coronal fricative $[\theta]$ (or $[ð]$ ). Second, some consonants were now being specified for place,

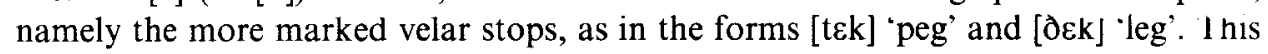
is in contrast to the absence of any place specification in consonants observed in the earliest phases of normal acquisition. Third, the directionality of place assimilation was apparently more constrained. Spreading was not bidirectional as in the younger normally developing children. This can be attributed to the fact that some final consonants were already specified for place, whereas initial consonants were not specified. Thus, the only possible target for the spreading was the initial consonant. From these data it is predicted that, in the course of acquisition, certain changes may be evidenced in a child's rules and representations. These may involve the range of segments that undergo a rule, the degree of consonant specification, and the directionality of the rule.

The patterning of consonants and vowels in a second case involving a phonologically disordered child provides further evidence of change in consonant-vowel interactions that may occur with development (Camarata and Gandour, 1984). The 

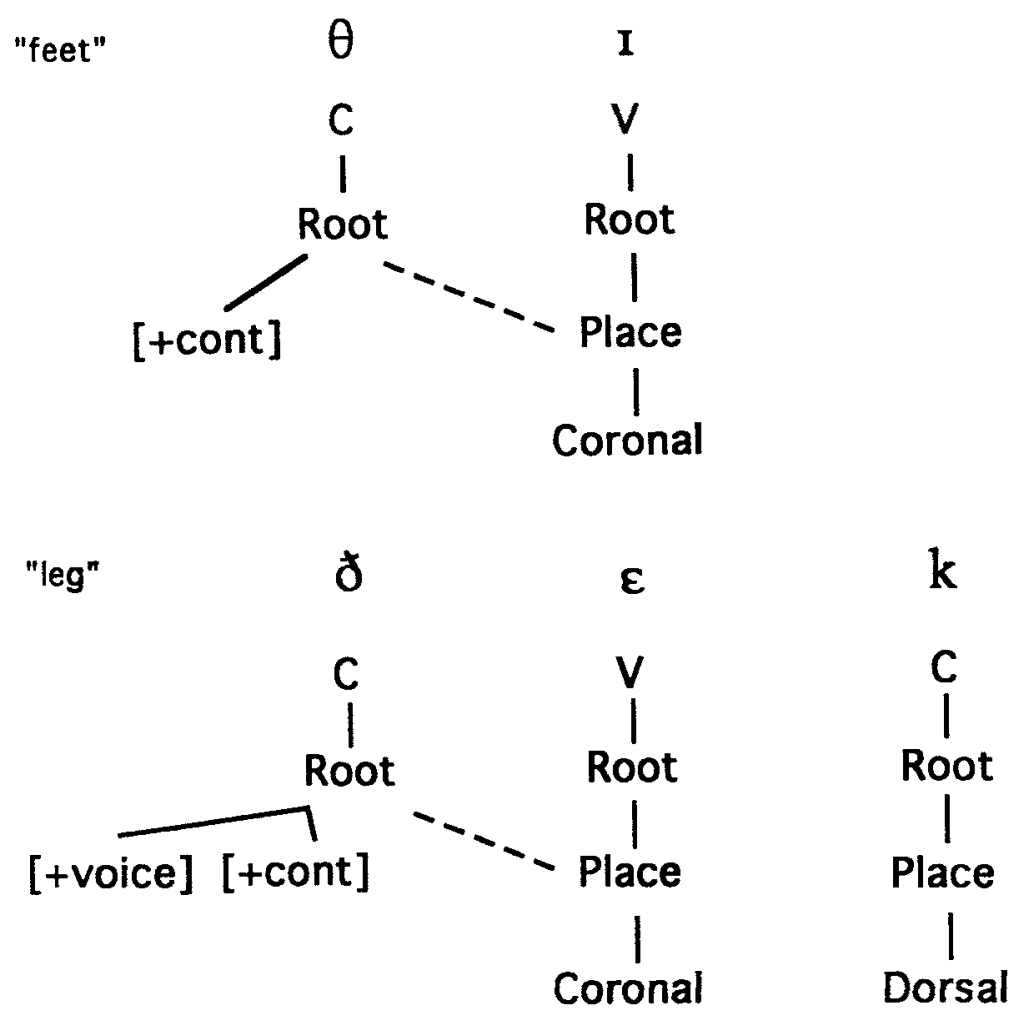

Figure 8. Derivations of forms produced by S3 (Grunwell, 1981) showing the leftward spreading of vowel place features to continuant (i.e. [+cont]) segments.

child G.G. maintained complementary distribution between alveolar and velar stops, such that coronals always and only occurred before high vowels, whereas dorsals always and only occurred before non-high vowels as in (6). (Labial consonants occurred before both high and non-high vowels.)

(6) G.G. (2;10 years)

[di] 'tea', 'key', 'kick'

[du] 'two', 'cook'

[ga] 'car', 'dog'

[gæ] 'kite', 'tie'

[ga] 'cup', 'duck'

[gær] 'clown', 'train'

[go] 'goat', 'toe'

At first glance it would appear that the distribution of alveolar and velar consonants is not conditioned by frontness or backness of the vowels, and therefore could not be accounted for by the spreading of vowel place features. ${ }^{6}$ The forms [du] 'two', 'cook, [gæ] 'kite', 'tie,' and [gæn] 'clown', 'train' are especially problematic in this

\footnotetext{
${ }^{6}$ This assumes that place features in the geometry are determined articulatorily. If, however, some geometries determine place features acoustically, it may be possible that the diffuseness of the vowel could spread to consonants, yielding agreement between consonants and vowels in terms of diffuseness.
} 
regard because coronal $[\mathrm{d}]$ occurred before a back vowel $[\mathrm{u}]$, and dorsal $[\mathrm{g}]$ before a front vowel $[\mathfrak{x}]$. There are at least two possible interpretations of these data. One obvious interpretation is that the apparent complementary distribution of stops is accidental, suggesting that alveolar and velar consonants are in fact distinct phonemes for this child. This would be similar to the observed complementary distribution of [ $\mathrm{g}]$ and [h] in English, despite the fact that these segments are also acknowledged to be associated with distinct phonemes.

The more likely possibility is that the place of articulation of consonants was determined from the place of vowels all along for this child, but that the fully integrated geometry characteristic of the earliest periods of acquisition was beginning to undergo change. This change may have been realized in one of two ways. Perhaps the fully integrated geometry was being elaborated, with some consonants now being specified for place in some words. In this case the geometric model of representation would remain the same, but its given structure would be more elaborate. It is also possible that the fully integrated geometry was undergoing planar restructuring. Consonants and vowels once tightly linked on the same tier may have been gaining independence, as in a partially segregated geometry. Consequently, the place of consonants could no longer be affected by the place of vowels in all instances for this child. Cases of this sort may be indicative of an intermediate step in acquisition. That is, children may modify their initial fully integrated geometry through elaboration of consonantal place specifications or through restructuring the geometry to be more in line with a partially segregated representation.

We will now turn to a third case from phonological disorders which examines directly individual differences in the representation of consonant-vowel interactions in development.

\section{Individual differences in phonological acquisition}

Williams and Dinnsen (1987) also observed a case of complementary distribution in the patterning of stops in N.E., a phonologically disordered child. As in previous cases, coronals occurred before front vowels, velars before back vowels, and labials before both front and back vowels as illustrated by the data in (7). A reinterpretation of these data within a geometric framework provides an assimilatory account that involves the spreading of coronal and dorsal vowel place, as shown in the derivations in Fig. 9. Vowels are prevented from influencing the place of articulation of labial consonants because labial place must be specified given the occurrence of both front and back vowels with labial consonants in this child's system.

(7) N.E. $(4 ; 6$ years $)$

\begin{tabular}{|c|c|c|c|}
\hline $\begin{array}{l}{[\mathrm{tci}]} \\
{[\mathrm{te}]} \\
{[\mathrm{tuku}]}\end{array}$ & $\begin{array}{l}\text { 'catching' } \\
\text { 'cage' } \\
\text { 'chicken' }\end{array}$ & $\begin{array}{l}{[\mathrm{d} \varepsilon]} \\
{[\mathrm{de} P]} \\
{[\mathrm{dr}]} \\
{[\mathrm{div}]}\end{array}$ & $\begin{array}{l}\text { 'leg', 'dress' } \\
\text { 'gate' } \\
\text { 'swim' } \\
\text { 'deer' }\end{array}$ \\
\hline [ko] & 'comb' & [go?] & 'goat' \\
\hline [ku?] & 'soup' & {$\left[\mathrm{gu}^{\mathrm{h}}\right]$} & 'tooth' \\
\hline$[\mathrm{ka}]$ & 'Tom' & [ga] & 'dog' \\
\hline$\left[\mathrm{ka}^{\mathrm{h}}\right]$ & 'cough' & [gah] & 'wash' \\
\hline$[\mathrm{kv}]$ & 'hill' & [go] & 'girl' \\
\hline
\end{tabular}


(a) "swim"

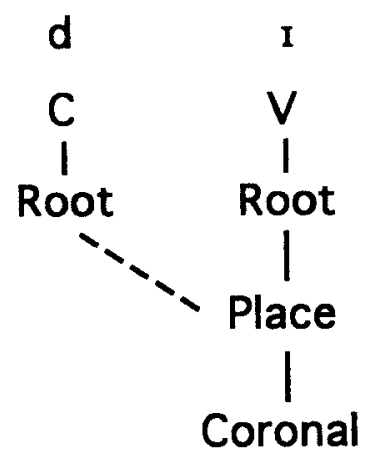

(b) "Tom"

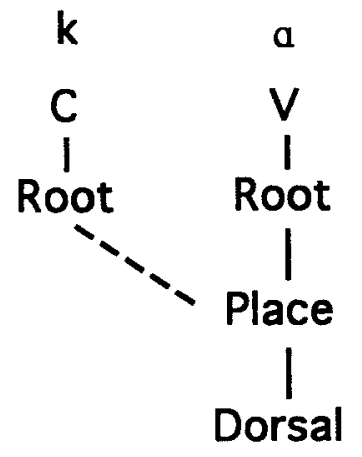

(c) "comb"

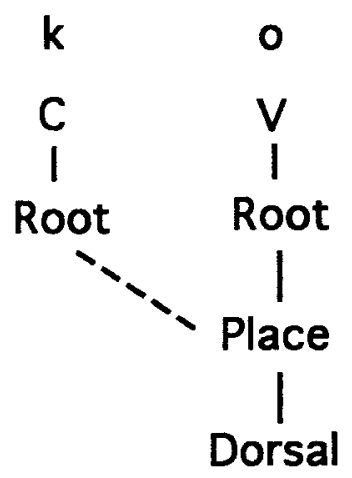

Figure 9. Derivations of forms produced by N.E. (Williams and Dinnsen, 1987) showing the spread of vovel place, lielding coronal $(a)$ and dorsal $(b, c)$ consonants.

$\begin{array}{llll}{[\mathrm{pl}]} & \text { 'pinch' } & {[\mathrm{bI}]} & \text { 'big' } \\ {\left[\mathrm{pu}^{\mathrm{h}}\right]} & \text { "push' } & {[\mathrm{bur}]} & \text { 'book', 'boot' } \\ {[\mathrm{pir}]} & \text { "peach' } & {[\mathrm{b}]} & \text { 'bed' } \\ {[\mathrm{pe}]} & \text { 'page' } & {[\mathrm{bo}]} & \text { 'blow' }\end{array}$

What is peculiar about this child's system. however, is the representation of back round vowels. Notice that for N.E., back round vowels were associated with the dorsal place (e.g. Figure 9(c)). This is in direct contrast to the pattern reported above for Fudge's son in (3) and Figure 7(a), where back round vowels were associated 
with the labial place. Recall that Fudge's son produced alveolars with front vowels, labials with back round vowels, and velars with back unround vowels. These differences in the representation suggest that the place specification of back round vowels may vary in developing systems, with associations to either the dorsal or labial node. The reason for this variation may lie in the composition of the inventories of these two phonological systems. Specifically, Goad (1992) hypothesized that the inventory of a language will determine specifically the featural specification of underlying representations in development (also Archangeli, 1988; Abaglo and Archangeli, 1989). Based on evidence from vowel harmony in fully developed systems, Goad demonstrated that the feature [round] would be selected instead of [front] in triangular vowel systems of languages such as Okpe, Igbo, and Igbirra. Conversely, the feature [front] would be selected over [round] in quadrangular vowel systems, such as Chamorro. Inventory specific underspecification of vowels thus may provide a plausible account of the differences observed in the representation of vowels in these two developing systems, as is considered below.

The vowel inventories of N.E. and Fudge's son are shown in (8). For N.E., labial place was not necessary to differentiate among vowels in the system. Coronal and dorsal alone distinguished front from back vowels. Of course, in order to fully differentiate among coronal and dorsal vowels there would need to be further height distinctions. However, the roundness of back vowels was totally predictable based on vowel height. That is, non-low back vowels were [+round] and the low back vowel was [-round]. N.E.'s vowel inventory, then, is comparable to a quadrangular system where the feature [front] (associated with the coronal node) must be selected over labial. In this case, labial was not active for vowels in the underlying representation. Moreover, labial was a specified place property for consonants given that labial consonants occurred before both front and back vowels in this child's system.

(8) Vowel Inventories

N.E.

$\begin{array}{lll}\text { Coronal } & & \text { Dorsal } \\ \mathrm{i} & & \mathrm{u} \\ \mathrm{I} & & \mathrm{u} \\ \mathrm{e} & & \mathrm{o} \\ \varepsilon & & \mathrm{a} \\ \text { Fudge's son } & & \\ \text { Coronal } & \text { Labial } & \text { Dorsal } \\ \mathrm{i} & \mathrm{o} & \mathrm{u} \\ \mathrm{e} & 0 & \mathrm{u}\end{array}$

In contrast, the vowel inventory of Fudge's son required a labial place node. Because there were both back round and back unround vowels of the same height in this child's inventory, it was necessary to differentiate back round vowels by labial place and back unround vowels by dorsal place. Therefore, this child's vowel inventory resembles a triangular system, where labial must be selected because it is relevant to the underlying representation of these vowels.

Individual differences in the representation of consonant-vowel interactions thus may be dependent on the structure of children's inventories. It is interesting that, even for children acquiring the same language, differences may emerge in the representation of phonological information. It will be important to establish whether 
these differences will also have empirical consequences for the subsequent course of phonological development within the framework of feature geometry.

\section{Implications for theories of language acquisition and feature geometry}

The evidence from consonant-vowel interactions in developing systems raises several important issues and hypotheses for both a theory of acquisition and for a theory of feature geometry. For acquisition, these data indicate that consonant-vowel interactions will likely be observed as an intermediate phase that takes place some time between the onset of vowel acquisition and the completion of consonant acquisition in meaningful speech. At the point of consonant-vowel interactions, children do not seem to distinguish place distinctively in both categories, vowel and consonant. Only vowels are specified for place; consonant place will generally result from an assimilatory process. This might seem to be in conflict with notions of selection and avoidance in early child phonology (e.g. Ferguson and Farwell, 1975; Leonard, Schwartz, Folger, and Wilcox, 1978; Schwartz and Leonard, 1982; Vihman, 1981), where the emphasis is on consonant as opposed to vowel distinctions. The claim has been that children select and avoid certain segments based on an awareness of target consonants that are either compatible or incompatible with the consonantal repertoire of their own phonological systems. However, a recent evaluation of the phenomenon of selection-avoidance suggests that at best it is ephemeral and not likely attributable to phonological factors (Dobrich and Scarborough, 1992).

Further, it appears that the weakest associations in consonant-vowel interactions will involve labial consonants and round vowels. The evidence supporting this claim comes from children G.G. and N.E., who produced labials before all vowel types. In these cases labials did not interact with neighbouring vowels, but coronals and dorsals did. This may be attributed to the independence of certain articulators. Namely, labial consonants are produced with the lips, whereas round (back) vowels are produced with the tongue (Davis and MacNeilage, 1990, p. 26). Further, round vowels have an ambiguous primary articulator, being associated with either labial or dorsal properties. In contrast, the most persistent interactions (at least for English) will presumably involve either coronal consonants and front vowels or velar consonants and back vowels. Although the data reported herein cannot designate a precedence between these couplings, it is predicted that the association of coronals will be most salient and thus most persistent. One possible reason again relates to articulatory compatibility. Namely, front vowels belong singularly to the coronal node (like coronal consonants), whereas back vowels share dorsal properties with round vowels. Additionally, the underspecified character of coronal consonants may render them especially vulnerable to the influence of phonetically adjacent vowels (Paradis and Prunet, 1991). Thus, labial may be the first, and coronal the last place of articulation where the interactions of consonants and vowels will diminish with development.

Such changes in the degree and nature of consonant-vowel interactions that occur in the course of acquisition also have further consequences for understanding the development of feature geometry. Ultimately, consonant-vowel assimilations must cease if the child is to acquire a target-appropriate, fully developed phonological system of English, because consonants do contrast in place before a full range of vowels in this language. There are two possibilities for the way in which this may be achieved: one does not involve restructuring the geometric representation, the 
other does. Considering the first possibility, the spreading of place from an adjacent vowel may decline with a modification of the assimilation rule. Perhaps, the domain and/or directionality of rule application may narrow, as was observed in the case reported in (5). In conjunction with this, spreading may also decline because of an elaboration of the existing geometric representation of consonants. That is, those consonants not previously specified for place may now be marked. While the phonological representation would be expanded to include the place dimension in consonants, the model of geometry itself would not be changed.

The more extreme case, however, would be for the child to restructure the geometric representation itself. As supported by the data in (1), (2), and (3), young children seem to prefer initially a full integration model of segment structure. Yet, for fully developed English, a partially segregated geometry has been argued to be the most appropriate representational model (Wolfram and Johnson, 1982, p. 91). Perhaps, with development, there may be a transition from a fully integrated to a partially segregated geometry, with increasing tier differentiation between consonants and vowels. ${ }^{7}$ Ultimately, a shift in the representational structure of this type would bring the child's phonological system more in line with the target language.

For a theory of language, the data regarding consonant-vowel interactions highlight two important differences between developing and fully developed phonological systems. First, in developing systems, consonant-vowel interactions determine primary articulations of consonants since only vowels are specified for place. In contrast, for fully developed systems, both consonants and vowels are specified for all relevant places of articulation (except, of course, for the unmarked or underspecified value of place). Consequently, consonant-vowel interactions can occur only in the form of secondary articulations for consonants (Clements, 1991). Secondary assimilatory processes observed in fully developed systems thus may be a residual of the primary processes of phonological development. This difference is significant because it underscores the importance of examining the course of acquisition as a means of gaining insight into the structure of fully developed systems.

A second difference between developing and fully developed systems relates to the degree of place specification in the geometric representation of vowels, in particular. Following Goad's (1992) proposal, certain vowels are specified and others radically underspecified in fully developed systems (Archangeli, 1988; Sanders, 1974; Stemberger, 1992). In particular, front vowels are radically underspecified in triangular systems, and back vowels in quadrangular systems. However, in developing systems, it appears that all vowels must have some place specification regardless of inventory type. In order for observed consonant-vowel assimilations to occur, vowels must be contrastively specified for place with no radically underspecified vowels (Clements, 1987; Steriade, 1987). Furthermore, in developing systems the specification of vowels is incomplete since height distinctions are still emerging ((8) herein; also Fee, 1991; Otomo and Stoel-Gammon, 1992). Perhaps, when contrastive height and place distinctions are acquired for vowels, the child will then have sufficient information to select one vowel as radically underspecified in the language. For the

\footnotetext{
${ }^{7}$ There are also alternative paths whereby the geometry may change from a fully integrated representation to one that is fully segregated. Evidence of this progression would come in the form of phonetically non-adjacent consonant or vowel harmonies (e.g. Smith, 1973; Grunwell, 1981).
} 
development of feature geometry, then, an additional prediction is that structure building will first involve place, and later height distinctions for vowels.

In conclusion, the interactions of consonants and vowels in developing systems provide support for a full integration model of feature geometry as a possible early starting point of phonological acquisition. This model is not static, however, and changes must be made in order that a child's system more closely resembles the fully developed target language. Changes may range from simple modifications of the assimilatory rule to more dramatic restructuring of the phonological representation itself. These changes provide a testing ground for determining the acquisition of feature geometry, and for establishing an empirically valid geometry that can account for phenomena in both developing and fully developed phonological systems.

\section{Acknowledgements}

This research was supported in part by grants from the National Institutes of Health (DC 00433, DC 01694, DC 00076, DC 00260) to Indiana University, Bloomington. Steve Chin and Stuart Davis provided helpful comments.

\section{References}

ABAglo, P. and ARChangeli. D. (1989) Language-particular underspecification. Linguistic Inquiry, 20, 457-480.

Archangeli, D. (1988) Aspects of underspecification theory. Phonology, 5, 183-207.

BERNHARDT, B. (1992a) Developmental implications of nonlinear phonological theory. Clinical Linguistics and Phonetics, 6, 259-281.

BernhaRDT. B. (1992b) The application of nonlinear phonological theory to intervention with one phonologically disordered child. Clinical Linguistics and Phonetics, 6, $283-316$.

Bernhard, B. and Gll Bert, J. (1992) Applying linguistic theory to speech-language pathology: the case for nonlinear phonology. Clinical Linguistics and Phonetics, 6, $123-145$

Braine, M. D. S. (1974) On what might constitute a learnable phonology. Language, 50, $270-300$.

Camarata. S. and Gandour. J. (1984) On describing idiosyncratic phonological systems. Journal of Speech and Hearing Disorders, 49, 262-266.

CHIN, S. B. and DinNsen. D. A. (1991) Feature geometry in disordered phonologies. Clinical Linguistics and Phonetics, 5, 329-337.

ChIN, S. B. and Dinnsen, D. A. (1992) Consonant clusters in disordered speech: constraints and correspondence patterns. Journal of Child Language, 19, 259-285.

Clements, G. N. (1985) The geometry of phonological features. Phonology, 2, 223-250.

Clements. G. N. (1987) Phonological feature representation and the description of intrusive stops. Chicago Linguistic Society, 23, 29-50.

Clements. G. N. (1989) A unified set of features for consonants and vowels. Unpublished manuscript, Cornell University.

Clements. G. N. (1991) Place of articulation in consonants and vowels: a unified theory. In B. Laks and A. Railland (eds.). L'Architecture et la Géométrie des Representations Phonologiques (Paris: CNRS).

Davis. B. L. and MaCNeilage. P. F. (1990) Acquisition of correct vowel production: a quantitative case study. Journal of Speech and Hearing Research, 33, 16-27.

Dinnsen, D. A. (1992a) Underspecification in phonological disorders. In M. Eid and G. Iverson (eds.). Principles and Prediction: The Analysis of Natural Language: Papers in Honor of Gerald Sanders (Philadelphia: John Benjamins). 
DinNsen, D. A. (1992b) Variation in developing and fully developed phonologies. In C. A. Ferguson, L. Menn and C. Stoel-Gammon (eds.), Phonological Development: Models, Research, Implications (Timonium, MD: York).

Dobrich, W. and SCArborough, H. S. (1992) Phonological characteristics of words young children try to say. Journal of Child Language, 19, 597-616.

FEe, E. J. (1991) Underspecification, parameters and the acquisition of vowels. Unpublished PhD thesis, University of British Columbia.

FERGUSON, C. and FARWELL, C. (1975) Words and sounds in early language acquisition. Language, 51, 419-439.

FUDGE, E. C. (1969) Syllables. Journal of Linguistics, 5, 253-286.

Gierut, J. A. (1986) Sound change: a phonemic split in a misarticulating child. Applied Psycholinguistics, 7, 57-68.

GiERUT, J. A. (1989) Developing descriptions of phonological systems: a surrebuttal. Applied Psycholinguistics, 10, 469-473.

GOAD, H. (1992) Learnability and inventory-specific underspecification. Paper presented at the annual meeting of the Linguistic Society of America, Philadelphia, January.

Goldsmith, J. (1979) Autosegmental Phonology (New York: Garland Press).

Grunwell, P. (1981) The Nature of Phonological Disability in Children (New York: Academic Press).

Hume, E. (1992) Front vowels, coronal consonants and their interaction in nonlinear phonology. Unpublished PhD thesis, Cornell University.

Ingram, D. (1989) First Language Acquisition (Cambridge: Cambridge University Press).

IVERSON, G. K. and WhEELER, D. (1987) Hierarchical structures in child phonology. Lingua, 73, 243-257.

JAKOBSON, R. (1968) Child Language, Aphasia, and Phonological Universals (A. R. Keiler, trans., original work published 1941) (The Hague: Mouton).

Kent, R. D. and Murray, A. D. (1982) Acoustic features of infant vocalic utterances at 3, 6 and 9 months. Journal of the Acoustical Society of America, 72, 353-365.

LAHIRI, A. and Evers, V. (1991) Palatalization and coronality. In C. Paradis and J. F. Prunet (eds.), Phonetics and Phonology, Vol, 2; The Special Status of Coronals: Internal and External Evidence (San Diego: Academic Press).

Le Normand, M. T. and Chevrie-Muller, C. (1991) A follow-up case study of transitory developmental apraxia of speech: 'L'enfant à voyelles'. Clinical Linguistics and Phonetics, 5, 99-118.

LeONARD, L. B. and Brown, B. L. (1984) Nature and boundaries of phonologic categories: a case study of an unusual phonologic pattern in a language-impaired child. Journal of Speech and Hearing Disorders, 49, 419-428.

Leonard, L., Schwartz, R., Folger, M. and Wilcox, M. (1978) Some aspects of child phonology in imitative and spontaneous speech. Journal of Child Language, 5, 403-416.

LEvelT, C. C. (1992) Consonant harmony: a reanalysis in terms of vowel-consonant interaction. Amsterdam Series in Child Language Development (In press).

MCCARThy, J. J. (1988) Feature geometry and dependency: a review. Phonetica, 43, 1-25.

Otomo, K. and Stoel-gammon, C. (1992) The acquisition of unrounded vowels in English. Journal of Speech and Hearing Research, 35, 604-616.

Paradis, C. and Prunet, J. F. (eds.) (1991) Phonetics and Phonology, Vol. 2: The Special Status of Coronals: Internal and External Evidence (San Diego: Academic Press).

RICE, K. (1992) On deriving sonority: a structural account of sonority relationships. Phonology, 9, 61-99.

RiCE, K. and Avery, P. (1991) Segmental complexity and the structure of inventories. Paper presented at the GLOW workshop on the acquisition of phonology, Leiden, March.

SAGEY, E. (1986) The representation of features and relations in nonlinear phonology. Unpublished $\mathrm{PhD}$ thesis, MIT.

SANDERS, G. A. (1974) The simplex-feature hypothesis. Glossa, 8, 141-192.

SCHEIN, B. and Steriade, D. (1986) On geminates. Linguistic Inquiry, 17, 691-744.

SCHWARTZ, R. and LeONARD, L. (1982) Do children pick and choose? An examination of phonological selection and avoidance in early lexical acquisition. Journal of Child Language, 9, 319-336. 
Smith. N. V. (1973) The Acquisition of Phonology' (Cambridge: Cambridge University Press). STEMBERger, J. P. (1992) Vocalic underspecification in English language production. Language, $68,492-524$

Stemberger, J. P. and Stoel-Gammon, C. (1991) The underspecification of coronals: evidence from language acquisition and performance errors. In C. Paradis and J. F. Prunet (eds.). Phonetics and Phonology, Vol. 2: The Special Status of Coronals: Internal and External Evidence (San Diego: Academic Press).

Steriade, D. (1987) Redundant values. Chicago Linguistic Society, 23, 339-362.

StOEL-Gammon, C. (1983) Constraints on consonant-vowel sequences in early words. Journal of Child Language, 10, 455-457.

Stoel-Gammon, C. and Dunn. C. (1985) Normal and Disordered Phonology in Children (Baltimore: University Park Press).

Vihman, M. M. (1981) Phonology and the development of the lexicon: evidence from children's errors: Journal of Child Language, 8, 239-264.

Vihman, M. M. (1992) Early syllables and the construction of phonology. In C. A. Ferguson, L. Menn and C. Stoel-Gammon (eds.), Phonological Development: Models, Research, Implications (Timonium. MD: York).

Weismer, G.. Dinnsen, D. A. and Elbert, M. (1981) A study of the voicing distinction associated with omitted. word-final stops. Journal of Speech and Hearing Disorders, 46, 320-328.

Williams, A. L. and Dinnsen, D. A. (1987) A problem of allophonic variation in a speech disordered child. Innovations in Linguistics Education, 5, 85-90.

Wolfram, W. and Johnson, R. (1982) Phonological Analysis: Focus on American English (Washington. DC: Center for Applied Linguistics). 